\title{
Personality and Psychopathology: a Theory-Based Revision of Eysenck's PEN Model
}

\author{
Dirk van Kampen*
}

Department of Clinical Psychology, Vrije Universiteit, van der Boechorststraat 1, 1081 BT Amsterdam, The Netherlands

\begin{abstract}
The principal aim of this paper is to investigate whether it is possible to create a personality taxonomy of clinical relevance out of Eysenck's original PEN model by repairing the various shortcomings that can be noted in Eysenck's personality theory, particularly in relation to $\mathrm{P}$ or Psychoticism. Addressing three approaches that have been followed to answer the question 'which personality factors are basic?', arguments are listed to show that particularly the theoryinformed approach, originally defended by Eysenck, may lead to scientific progress. However, also noting the many deficiencies in the nomological network surrounding P, the peculiar situation arises that we adhere to Eysenck's theoryinformed methodology, but criticize his theory. These arguments and criticisms led to the replacement of $\mathrm{P}$ by three orthogonal and theory-based factors, Insensitivity (S), Orderliness (G), and Absorption (A), that together with the dimensions $\mathrm{E}$ or Extraversion and $\mathrm{N}$ or Neuroticism, that were retained from Eysenck's PEN model, appear to give a comprehensive account of the main vulnerability factors in schizophrenia and affective disorders, as well as in other psychopathological conditions.
\end{abstract}

\section{INTRODUCTION}

Since the early days of psychiatry, clinicians have speculated about the precise relationships between personality and psychopathology. The dominant position has been that personality forms the background from which psychiatric illnesses emerge rather than the other way round [1]. According to Kraepelin, for instance, aberrant personality traits may actually constitute the first expression in infancy of later developing dementia praecox/schizophrenia [2], while Sullivan claimed that "mental disorder must be regarded as the result of the personality relating to the demands of the personal situation" [3]. Clinical psychologists studying the relationship between personality and psychopathology have often shown interest in Eysenck's PEN model [4]. This is not surprising as the proposed dimensions of this model grew out of previous attempts by Jung and Kretschmer to link their personality schemes to the main types of neurotic and psychotic disorder as originally described by Janet and Kraepelin (see, e.g., [5,6]). For Eysenck, however, the existence of the dimensions Psychoticism (P), Extraversion (E), and Neuroticism (N) can only be definitely accepted, provided that they also have been deduced from psychological theories related to findings in learning theory, genetics, physiology, perception, psychopharmacology and many other disciplines [7-9]. In other words, the clinical dimensions P, E, and $\mathrm{N}$ can only be described as 'basic', 'major' or 'fundamental' $[10,11]$ because of their demonstrated embeddedness - at least in the eyes of Eysenck - in a general causative theory from which testable deductions were made that could be confirmed. Notwithstanding the traditional emphasis here on the concept of construct validity (see also [12,13]), Ey-

\footnotetext{
*Address correspondence to this author at the Department of Clinical Psychology, Vrije Universiteit, van der Boechorststraat 1, 1081 BT Amsterdam, The Netherlands; Tel: +31 20 5988876; Fax: +31 20 59888758;

E-mail: d.van.kampen@psy.vu.nl
}

senck's PEN model has more recently attracted less attention, mainly because of the now widely held view, both in and outside clinical psychology, that with the advent of the Big Five [14], FFM [15], and HEXACO models [16], the question of which personality factors are basic has been definitely settled. Although Eysenck's $\mathrm{E}$ and $\mathrm{N}$ factors appear in these latter models too (together with, for instance, the FFM dimensions Agreeableness, Conscientiousness, and Openness to Experience), the measurement of $\mathrm{P}$ was regarded to be superseded, because this dimension could not be recovered in, for instance, Goldberg's lexical Big Five studies that aimed to identify those factors that represent the total personality sphere. Moreover, several authors, among them Davis [17], Bishop [18], and Zuckerman, Kuhlman \& Camac [19], questioned the validity of the $\mathrm{P}$ scales constructed by Eysenck, because these scales appeared to be much stronger related to psychopathy, drug addiction and criminality than to psychosis, the area of psychopathology that was originally intended to be assessed by these scales.

Although the lexically-based models undoubtedly will be, and have already been, found to correlate with psychopathology [20], these correlations do only reflect content validity as the personality measures applied in these investigations could not be validated by using relevant criteria that are part of a nomological network in which the various personality constructs are embedded. Because the Big Five and HEXACO dimensions do only rest on factorial studies, it comes as no surprise that Eysenck considered his own PEN model and the methodology used to arrive at this model to be clearly superior. A similar conclusion can be drawn if Eysenck's model is compared with the FFM, for although one cannot deny that the FFM dimensions Neuroticism, Extraversion and Openness to Experience were originally selected for more or less theoretical reasons [21], the FFM as currently understood must be regarded to provide a truly 'exhaustive' taxonomy of descriptive personality features that 
fully accords with the results of previous Big Five studies [15]. Even later attempts by McCrae and Costa to link their dimensions to clinically important theoretical constructs like Freud's narcissism or Horney's tendency to move against people, were only taken in retrospect, that is, after having selected the FFM factors because of their similarity with Goldberg's Big Five dimensions [22].

The main purpose of the present paper is to look anew at Eysenck's personality model. More specifically, we want to investigate whether it is possible to create a personality taxonomy of clinical relevance out of the original PEN model by repairing the various shortcomings that can be noted in Eysenck's underlying theory, particularly in relation to $\mathrm{P}$ or Psychoticism. By 'clinical relevance' we mean that the taxonomy's dimensions must refer to personality traits that make individuals vulnerable to the development of psychiatric disorder, thus upholding the traditional view about the nature of the relationship between personality and psychopathology. Additionally, as at least some Axis II personality disorders show symptomatic overlap with particular Axis I clinical syndromes [23], the intended dimensions may also provide a sound basis for improving the classification of mental disorders. As such, the present paper addresses a timely issue as dimensional models of personality are of considerable interest as the field moves toward DSM-V [24].

The question how to arrive at a set of basic personality factors that are of clinical interest will be addressed here by applying the same theory-informed methodology as used originally by Eysenck in his attempts to demonstrate the construct validity of the dimensions $\mathrm{P}, \mathrm{E}$, and $\mathrm{N}$. This time, however, we will also take into account those theoretical data and arguments offered by Eysenck that are not justified. As such, attention will be paid to several topics, among which Eysenck's claim that all functional psychoses are genetically related and do not form distinct categories; the theory that psychotic disorders, via a spectrum of non-psychotic states (e.g., schizoid disease and criminality), are continuous with normal behavior; and Eysenck's belief that his EPQ-P scale [25] actually measures Psychoticism, notwithstanding its antisocial and psychopathic contents. As, however, not only Eysenck's PEN model, but also the Big Five, FFM and HEXACO models all claim to embrace basic dimensions of personality, we will not simply stick to Eysenck's assertion that only his own methodology can be trusted, and that the statistical approach advocated, for instance, by Goldberg leads at best to arbitrary results $[10,11]$. Rather, we want to compare these different methodologies, looking for their relative strengths and weaknesses. As the choice of a certain methodology always precedes the establishment of a particular model, we will first present such a comparison (also including the so-called heuristic approach; see below), whereas Eysenck's $\mathrm{P}$ theory and the clinical taxonomy we propose instead of Eysenck's PEN model are discussed in the sections that follow.

\section{METHODOLOGICAL CONSIDERATIONS}

One of the main debates in personality psychology in the last decennium of the $20^{\text {th }}$ century concerned the question 'which personality factors are basic?' and 'what are the criteria to determine that a personality factor is basic?' $[10,11$, 22, 26-28]. According to Eysenck [10], three approaches have been followed to address these questions: (1) the 'heuristic' approach, (2) the approach advocated by Cattell and by the Big Five proponents (and later by the designers of the HEXACO model), and (3) the theory-informed approach followed by Eysenck himself.

\section{Heuristic Trait Models}

In Eysenck's view, heuristic personality psychologists follow 'a pre-conceived notion of what traits might be important, or indeed what traits might or might not exist, or else (...) adopt some psychiatric system of classification' [10]. The ensuing models are sometimes criticized by Eysenck because of their psychometric inadequacies. However, these criticisms are not held to be of great importance, for Eysenck admits that some heuristic inventories may have 'reasonable psychometric parentage' [26]. Of more importance, then, is Eysenck's second point of criticism, according to which heuristic traits are 'not based on any theory of personality' [26], or - the other way round - are considered to be 'of little value for the creation of a proper scientific model of personality' [10]. What is meant by these statements might be inferred from a letter from Eysenck to Goldberg (February 27, 1995) that formed part of an ongoing discussion between the two authors about methodology and the place of theory and construct validity in personality psychology. In this letter - kindly made available to the present author by Goldberg ${ }^{1}$ (Personal communication, March 13, 1995) - Eysenck asserts that many so-called theories, such as those of Millon, Block, Bakan, and Tellegen, 'are essentially taxonomic', and, thus, that 'they do not begin to touch the root of the problem as not being "theories" in my sense at all. Notions begin to become theories when they leave the purely taxonomic field and incorporate testable causal assumptions'.

\section{The Psychometric Approach}

The second group of personality psychologists - Cattell and the proponents of the Big Five model - consists, according to Eysenck, 'of those who adopt a psychometric point of view, and would like to base their model of personality on complex factorial studies of the intercorrelations between traits' [10]. As is well-known, this characterization is obviously onesided, for, besides statistical arguments, the personality psychologists adhering to this position also defend their trait models on the basis of the lexical hypothesis. In fact, this hypothesis must be seen to offer the ultimate foundation behind this approach, whereas the use of factor analysis and other statistical techniques may be seen as merely auxiliary. However, for the moment, we will follow Eysenck in his discourse, which means that the lexical hypothesis will be mentioned only obliquely or not at all.

Compared with Eysenck's treatment of heuristic personality models, the work of the followers of the "psychometric approach' is usually addressed more favorably by him. Regarding their respective contributions, the results are said to be 'replicable (...) and there is considerable agreement be-

\footnotetext{
${ }^{1}$ Three letters are involved in this exchange of ideas: two from Eysenck to Goldberg (January 11, 1995; February 27, 1995) and one from Goldberg to Eysenck (February 6, 1995). For the sake of interest, or to elucidate a specific point, we will sometimes quote from these letters.
} 
tween leading exponents' [10]. Moreover, the differences between Cattell's 16 PF system and the Big Five model are believed to be 'only apparent', for the 16 dimensions proposed by Cattell (which must be seen as primary factors) have been found in factor analytic investigations to result in "a much smaller number of factors similar to those advocated by Eysenck and by the "Big Five" proponents' [10]. A less favorable view with respect to Cattell's model seems apparent in Eysenck's 1991 discussion of the present topic [26]. It might be true, states Eysenck, that Cattell has tried 'to cover the whole ground of personality - collecting relevant linguistic terms', the fact remains that the 16PF system in factor analytic studies fails to replicate. Similar criticisms can also be found in another paper by Eysenck, even to the point of classifying Cattell's model under the category of heuristic personality models because of its psychometric weaknesses [11].

The relatively benevolent view of Eysenck on the Big Five model has also its limits. A particularly weighty point for Eysenck with this model is that although the Big Five dimensions (or their non-lexical counterparts proposed by Costa \& McCrae [15]) seem to be well established, these factors actually refer to a mix of two second-order factors, namely, Extraversion (E) and Neuroticism (N), and three first-order dimensions, viz., Agreeableness, Openess to Experience, and Conscientiousness $[26]^{2}$. Support for this view is borrowed from a study by McCrae \& Costa, in which it was demonstrated that Agreeableness (A) and Conscientiousness (C) were both (negatively) correlated with Eysenck's P or Psychoticism dimension [30]. Hence, it seemed possible to regard the two Big Five factors as subfactors of $\mathrm{P}$. The same mixture of second- and first-order dimensions is also described in Eysenck's 1994a and 1994b publications $[10,11]$, in which mention is made of Goldberg \& Rosolack's finding that $\mathrm{A}$ and $\mathrm{C}$, when disattenuated, correlate 0.85 with $\mathrm{P}$ [28]. With these relationships, Eysenck obviously arrives at his 'own' personality dimensions $\mathrm{P}, \mathrm{E}$, and $\mathrm{N}$, making his PEN model a serious alternative compared with the Big Five system. A similar conclusion would almost certainly have been reached by Eysenck regarding Ashton's Big Six representation [31]. In that case, the HEXACO factors $\mathrm{H}$ (Honesty), A (Agreeableness), and C (Conscientiousness) would very likely have been regarded to negatively correlate with $\mathrm{P}$.

\section{Eysenck's Theoretical Approach}

The above-cited finding that $\mathrm{A}$ and $\mathrm{C}$ both correlate with $\mathrm{P}$ is for Eysenck insufficient reason to discard the two Big Five dimensions. Indeed, instead of concluding that A and C must be regarded as subfactors of $\mathrm{P}$, we may also arrive at Costa \& McCrae's [22] contention that $\mathrm{P}$ 'is a mere artifact, combining variance from A and C' [11]. So, the problem arises how to choose between these alternative positions.

\footnotetext{
${ }^{2}$ Ironically, Eysenck's criticisms with respect to the different hierarchical status of the Big Five dimensions also apply to his own model. According to recent research by Markon et al., $\mathrm{P}$ and $\mathrm{N}$ might be considered first-order dimensions of Alpha, as compared to the second-order status of Beta, which mainly resembles E [29]. However, with the dimensions Extraversion and Neuroticism emerging at several levels in Markon et al's scheme, the criticisms leveled by Eysenck are only valid in the case of a three-factor solution.
}

It is here that Eysenck introduces his own methodology for answering the question 'which personality factors are basic?' Factor analysis alone, states Eysenck, 'is too narrow a base from which to construct an adequate model' [10]. A solution should be arrived at in the combination of the two traditional disciplines in scientific psychology: the experimental and the correlational discipline. More specifically, the correlational approach in personality psychology must be grounded in a general theory or nomological network that permits experimental testing. Far more important than the criteria of factor replicability and the existence of higherorder factors that are similar to the dimensions $\mathrm{P}, \mathrm{E}$, and $\mathrm{N}$, Eysenck insists that 'In order to qualify as a major dimension of personality, any concept should be based on a general theory which has its antecedents in DNA (genetic analysis), and advances through biological intermediaries (psychophysiological, hormonal, etc.) to the dimensional and factorial analysis of behaviour and trait patterns. It should from there proceed to the experimental testing of the general theory, making deductions from the theory as to how people at various positions on the relevant personality dimensions would behave in carefully designed experimental situations. And finally one would expect that the theory, and the knowledge acquired through experimental study, should enable us to make predictions as to the general social behaviour of people in carefully defined situations. If the theory can accomplish that, then it might be used to define a dimension of personality which would have paradigmatic standing' $[10]^{3}$.

\section{Comprehensive Basic Factors}

Prior to describing the clinical nomological network that according to Eysenck naturally leads to the conclusion that $\mathrm{P}$ is a basic dimension of personality, two other points must be dealt with concerning Eysenck's view that only his theoryinformed approach may give a valid answer to the question as to which personality factors are basic: (1) the position of the adherents of the Big Five model with respect to that question, and (2) the objections they raise against Eysenck's claim that the Big Five and heuristic approaches in personality psychology are opposed to the 'theoretical' approach. As we will see, both issues may slightly weaken Eysenck's position in that the heuristic and phenotypic structure approaches comprise some elements that cannot be discarded, but nevertheless do not provide enough power to simply replace Eysenck's methodology.

In criticizing the Big Five model as a system of personality description that almost completely relies on psychometric and factor analytic studies, Eysenck failed to recognize the much greater importance attributed by their advocates - and by Cattell - to the lexical hypothesis. This hypothesis states that 'all aspects of human personality which are or have been of importance, interest, or utility have already become recorded in the substance of language' [36]. Goldberg explains

\footnotetext{
${ }^{3}$ As about fifty percent of the variance of personality traits derives from unshared environmental influences (see, e.g., [32]), the emphasis here on genetic and biological factors in defining a basic dimension of personality is clearly one-sided. Personality traits are actually an amalgam of behavioral dispositions present at birth (temperament) and life experiences [33], the latter probably mainly extra-familial [34]. From the perspective of psychopathology, we must also state that genetic vulnerabilities may never become apparent unless uncovered by specific environmental conditions [35].
} 
this phenomenon by arguing 'that the more important [an individual] difference is, the more people will notice it and wish to talk of it, with the result that eventually they will invent a word for it' [37]. Of course, in defending his own PEN model, Eysenck rightfully rejects the notion that this hypothesis has anything to do with psychological theory, as the lexical approach is only acquainted with language [10]. Other psychologists, like Allport and Block, though in Eysenck's view merely following the heuristic approach, underscore this position by noting that 'common speech is a poor guide to psychological subtleties' [38] and 'that, for scientific purposes, single-word descriptors $(\ldots)$ cannot convey crucial features of personality [and] its dynamic functioning' [39]. Nevertheless, the linguistic approach has some advantages, to which Eysenck seems almost completely unaware. Instead of claiming that a basic personality factor must have been shown to form part of a tested nomological network, the lexical approach has an open eye for the comprehensiveness of one or more dimensions. As noticed by Costa \& McCrae, 'Insuring that a personality system [such as the one proposed by Eysenck] includes all major domains of personality is problematic because there is no conclusive way to know that some set of traits has not been overlooked' [15]. However, embracing the lexical hypothesis, we are in the position to argue that the establishment of a truly 'exhaustive' taxonomy of personality features could proceed from a thorough examination (by means of synonym ratings, cluster analysis, and factor analysis) of all personality-descriptive terms contained in an unabridged dictionary. Hence, the basic character of a lexically-based personality dimension does not lie in the incorporation of a proper causal theory, but in the demonstration that that dimension accounts for a rather large part of total 'personality sphere' variance, which is represented by an essentially finite number of linguistic terms. What we thus see is that the linguistic hypothesis is said to offer an adequate procedure for sampling human traits, whereas cluster analysis and factor analysis are used as a method for structuring that sample of attributes [21].

Although several problems remain, particularly associated with the possibility of dimensions that exist beyond the Big Five, most results obtained in lexical personality studies, at least in Western industrialized countries, have been found to support the Big Five taxonomy, or at least a model that is more or less similar to that taxonomy. According to a study by Ashton et al., for instance, a cross-language six-factor solution appears appropriate, of which five factors are not greatly different from the Big Five dimensions Surgency, Agreeableness, Conscientiousness, Emotional Stability and Intellect [31]. It is from this demonstrated capacity that the Big Five model, in our opinion, might profitably be used as a yardstick to measure the degree to which heuristic or theoryinformed personality dimensions are 'exhaustive' by correlating these dimensions with the Big Five factors. Of course, the HEXACO model might also be selected for that purpose. Nevertheless, we must not forget that a basic dimension in the sense of Eysenck does not necessarily mean the demonstration of exhaustiveness, or vice versa. A basic dimension as understood by Eysenck may for instance be found to correlate with several Big Five factors, or only with a subdomain of personality characteristics associated with one of the lexical dimensions. Hence, we must conclude that when Eysenck and the adherents of the phenotypic structure approach speak about basic personality dimensions, they mean something completely different ${ }^{4}$.

\section{Inadequate Demarcations}

The second issue that must be discussed relates to the fact that Eysenck's [10] distinction between the heuristic, the Big Five, and his own theoretical approach is believed by the adherents of the Big Five model to give a rather false impression of the real demarcation lines in personality psychology. Eysenck's notion that the lexical approach is only concerned with a descriptive taxonomy of phenotypic personality features leaves two points out of consideration, namely (1) that the adherents of the Big Five model actually share this notion, and (2) that they hold that in science it has been often found useful, if not necessary, to develop a descriptive taxonomy prior to the establishment of a general causative theory [21].

With respect to the latter point, we must first reiterate that in Eysenck's approach the introduction of a personality dimension is closely related to the formulation of a psychological theory in which that dimension is embedded. This view is reminiscent of Eysenck's [40] definition of a theory as a nomological network, which in turn is defined as 'an interlocking system of lawful relations', consisting of 'both theoretical constructs and observable properties or operations' (see for a slightly different exposition: [41]). Thus, in the case of Eysenck's P theory, the statement that schizophrenia and manic-depressive illness are genetically related (see below) will naturally lead to the investigation of the genetic background of $\mathrm{P}$, for this dimension - at least as measured by the P scale of the Eysenck Personality Questionnaire [25] - was introduced to represent the genetic predisposition towards both psychoses. In contrast, no deductions can be made from whatever causal theory if we want to investigate the genetics of the Big Five dimensions Agreeableness and Conscientiousness, as these dimensions are only based on lexical studies. An even better example (also discussed below) is the testing of Eysenck's P theory by means of proportionality analysis, for the application of this method is indeed unthinkable in the case of the merely lexically and statistically derived dimensions just mentioned. Acknowledging then that the eventual formation of a causal theory after the establishment of a purely descriptive and lexically-based taxonomy remains possible, we have to conclude that Eysenck's approach has the great advantage to postulate dimensions that have led to the formation of a psychological theory from which testable hypotheses can be deduced - a theory that also gives direct psychological meaning to the positions obtained on these dimensions.

One further point related to the question whether it seems wise to develop a merely descriptive taxonomy prior to the establishment of a causal theory has also to do with this conclusion. For in Eysenck's opinion, his own approach must

\footnotetext{
${ }^{4}$ This is not to say that Eysenck sees no merit in exhaustive dimensions. At least on some occasions, Eysenck has defined the concept of 'basicality' to also include the notion that fundamental factors offer a comprehensive account of man's interpersonal conduct (see, e.g., [26] and Eysenck's letter to Goldberg from February 27, 1995).
} 
not only be regarded as fundamentally different from the lexical methodology, but also from the approach followed by the adherents of the heuristic school [10]. Of course, in emphasizing that a basic personality dimension must be embedded in a nomological network, the separate place of the heuristic approach is justified. However, if we ask for the origins of Eysenck's PEN model, this distinction becomes blurred, because, as Goldberg writes in his letter to Eysenck (February 6, 1995), 'it is not clear to the world at large how your PEN model is not well described as an example of the "heuristic" school, given that you explicitly adopted "some psychiatric system of classification" for P and N, and you used your own "notion of what traits might be important" to select E'. Therefore, instead of emphasizing the differences between Eysenck's methodology and the heuristic approach, pre-theoretical notions may be seen as actually constituting a necessary first step in the development of a causal theory along the lines advocated by Eysenck. Hence, Eysenck's assertion in his letter to Goldberg (February 27, 1995) that the theories of Millon, Block, Bakan, and Tellegen, as well as those of Cattell, Gough, Comrey and Guilford, are 'purely descriptive', and consequently 'all on a different planet to a proper causal theory', may be correct in so far as these authors have not presented any genetic, physiological, experimental or social-psychological evidence in support for their views, but the placement of all these 'theories' in a separate category of heuristic trait models misses the point that at least some of these views may grow into wellvalidated theories in the sense of Eysenck. Indeed, the suggestion often made by Eysenck (see, e.g., $[10,11]$ ) that it is actually only his PEN model that offers an answer to the question which personality dimensions are basic must be criticized as well, for, as Eysenck recently conceded, other psychologists, like Gray, Cloninger and Zuckerman, have also 'developed a nomological network making testable predictions of the kind here considered' [41]. In the present paper, however, we will only critically discuss the theory behind Eysenck's PEN model (in fact only the theory behind P, for it is especially the 'P part' of the model that contains elements that run counter to empirical fact) as we consider Eysenck's heuristic notion that the main diagnostic categories in psychiatry must somehow relate to the main dimensions of personality a suitable (but, of course, debatable) starting-point. Naturally, it is particularly in clinical psychology - the field of study of Eysenck and the present author - that such a notion makes sense; in non-clinical personality psychology, other pre-theoretical notions may be more relevant. Therefore, to sum up our methodological position, we have to conclude that from the three approaches listed by Eysenck for deciding on the constructs to be used in personality psychology [10], particularly Eysenck's theoryinformed approach can be expected to deepen our psychological understanding and to lead to progress in personality science, but that nevertheless heuristic notions, based on, for instance, intuition and observation, play a very important role in at least provisionally selecting the dimensions of interest. The lexical approach, although wholly appropriate if comprehensive personality factors are at stake, is unsuitable if our intention is to delineate specific personality dimensions that are embedded in a causal theory that has the ability to generate testable deductions. Hence, designed for different purposes, the lexical approach and the theory-informed methodology do not appear to exclude each other, making it almost unbelievable that both Eysenck and the adherents of the lexical approach often spoke of a 'seemingly intractable controversy' in need of 'a convincing solution' (see, e.g., [42]).

\section{EYSENCK'S P THEORY}

\section{Two Presuppositions About $P$}

Compared with Eysenck's E and $\mathrm{N}$ theories that are extensively investigated along biological and experimental psychological lines [8], Eysenck's P theory seems to be rather meagre. However, there are two presuppositions about $\mathrm{P}$ that Eysenck believes are well supported and that, hence, suggest that the Psychoticism model might at least be correct in broad outline. According to Eysenck, the first proposition states 'that all functional psychoses (schizophrenia, manicdepressive illness, schizoaffective disorders, monopolar depression) are related and do not form independent categories' [27]. Elsewhere, this presupposition is worded somewhat differently by stating that these illnesses 'form a definite continuum' from the least severe to the most severe [43], or that these illnesses 'have some fundamental psychological property in common' [11]. Eysenck's second presupposition is 'that psychoses as such are continuous with a whole spectrum of abnormal states (schizoid disorders, psychopathy, alcoholism, criminality) which occur significantly more frequently in relatives of psychotics, and shade into perfectly normal forms of behaviour' [27]. The common property of the psychoses, therefore, is not held to be 'categorical or qualitative, opposing psychotic to normal, but is dimensional or continuous, going from one extreme (psychosis) to its opposite' [11].

Although only marginally distinguished by Eysenck (see, e.g., [9]), there are actually two versions of each presupposition, associated with what we have elsewhere called the phenotypic and the genotypic P models [44]. This pairing is reminiscent of Andreasen's more global distinction between the phenomenotype (e.g., symptomatology) and the biotype (e.g., genetics and neurophysiology) in psychopathology two different fields of study that must be integrated if we want to identify and define a certain disorder [45]. However, as we discuss below, the phenotypic and the genotypic P models appear to be impossible to reconcile.

\section{Common Symptoms}

In the phenotypic variant of the first presupposition the common psychological property is simply defined as the symptomatic overlap of the various psychoses, particularly emphasizing the presence of psychotic symptoms, like hallucinations and delusions. Such a definition is hardly surprising, as it is precisely the fact that for disorders such as schizophrenia and manic-depressive psychosis to be called 'psychotic', they must have at least these symptoms in common which distinguish them from all other disorders.

\section{Common Genetics}

Compared with the phenotypic variant, the genotypic variant of the first presupposition appears to be more problematic. Instead of merely assuming a symptomatic relationship, schizophrenia and manic-depression, as well as other 
psychoses, are now believed to be caused by a common $g e$ netic defect. Furthermore, this common factor is also believed to underlie the emergence of several non-psychotic manifestations, in particular psychopathy, antisocial conduct, criminality and 'schizoidia' (e.g., schizotypal personality disorder), as these manifestations have been found, according to Eysenck, to occur rather frequently among biological relatives of schizophrenic and manic-depressive patients.

As to the psychoses, several studies are mentioned by Eysenck $[9,46]$, which according to him demonstrate that schizophrenia, manic-depression and other psychoses, although also showing some degree of biological specificity, are genetically related. However, as indicated elsewhere $[44,47]$, most of the empirical evidence actually points in a direction opposite to Eysenck's theory (see, e.g., [48]), albeit that that the relative risk for unipolar depression (but not for bipolar disorder, the condition most similar to manicdepressive insanity) perhaps might be slightly increased in first-degree biological relatives of schizophrenic probands [49]. Of course, there are recent linkage studies that suggest that schizophrenia and manic-depression share some susceptibility genes [50], but if these syndromes are defined as usual on the basis of a lifetime diagnostic hierarchy with schizophrenia at the top and bipolar disorder at a lower position, quantitative genetic studies have generally not demonstrated significant familial co-aggregation [51]. Moreover, a relaxation of that hierarchy - permitting, for instance, the recognition of mania as a separate disorder in the presence of typical schizophrenia - must be criticized, for it is known that the decompensation process in schizophrenia includes the occurrence of manic- and depressive-like symptoms $[52,53]$. With respect to other forms of psychosis (for instance, delusional and schizo-affective disorder), a genetic relationship with schizophrenia cannot be excluded [54], but these relationships hardly carry any weight here, as at least some of these conditions may simply be subsumed under the category of schizophrenic disorders, because the boundaries of the schizophrenia concept are still unclear [55].

The criticisms that can be leveled at Eysenck's nonpsychotic extension of the genetic generality hypothesis have also been previously discussed [44]. Besides the fact that only studies are mentioned that examined relatives of schizophrenics, and not relatives of patients with affective or other psychoses, the main criticism here relates to Eysenck's suggestion that all forms of psychopathy and antisocial conduct belong to the schizophrenia spectrum. This view, however, must be refuted as the genetic relationship concerns only the schizoid form of psychopathy that was originally described by Kallmann [56]. Nevertheless, we must not forget that several behaviors present in schizoid psychopathic individuals also occur among persons with classical psychopathy. If psychopathy is defined in terms of Cooke \& Michie's three-factor model [57], schizoid and classical psychopathy seem to have the 'affective style' and 'behavioral style' factors in common, but the schizoid form does not appear to be characterized by high scores on the 'interpersonal' factor. Replacing the older designation 'schizoid' by the more precise term 'schizotypal', a similar correction has to be made. Although we must confirm the place attributed by Eysenck of schizotypal personality disorder (and perhaps also of paranoid personality disorder) in the schizophrenia spectrum (see, e.g., [54]), it is important to note that these 'official' diagnostic categories do not seem to exhaust the many subtleties present in former descriptions of schizoid personality deviations found among biological relatives of schizophrenics $[58,59]$. Furthermore, these modern categories may be too 'broad' from a genetic perspective, as only 'negative' schizotypic features (like social anxiety and affective flattening), and not 'positive' or psychotic-like symptoms, are found to be more common among the relatives of schizophrenic probands [60].

\section{The Normality-Psychosis Continuum}

The phenotypic version of the second presupposition was initially put forward by Eysenck in 1952 [61]. At that time, Eysenck regarded $\mathrm{P}$ as 'a continuum which goes all the way from the perfectly normal, rational to the completely insane, psychotic individual'. The same view was echoed again in 1976, when Eysenck \& Eysenck wrote that 'the characteristics which differentiate normals from psychotics are infinitely graded, giving rise to all sorts of intermediate personalities from one extreme to the other' [6]. Although Eysenck [61] claims that the continuity hypothesis with regard to psychotic behavior has actually been verified by him, this claim is not justified, as the here demonstrated continuity does not reflect psychosis, but only the nature of the objective tests that were applied in Eysenck's study [44,62].

Nevertheless, there are other indications that offer support for some form of phenotypic continuity. We may, for instance, point to several studies discussed by Johns \& Van Os [63] in which it was demonstrated that both hallucinatory and delusion-like experiences are present in considerable proportions in normal samples. Also of interest is the finding, discussed by, for instance, Vollema \& Van den Bosch [64], that specific scales, constructed to measure psychoticlike symptoms in non-clinical samples define a factor of positive schizotypy (see, e.g., [65]) that appeared to be strikingly similar to one of the dimensions found in factor analytic studies of schizophrenic symptoms (e.g., [66]). Of course, the aforementioned continuity only concerns positions on Eysenck's normality-psychosis continuum that are more or less strongly associated with the psychotic extreme. Nowhere is a reference made to qualities that describe 'the perfectly normal, rational individual'. Although some form of discontinuity, which shows itself in a threshold effect, might also exist [67], this 'continuum-related discontinuity' effect has not been demonstrated convincingly, and, thus, we may still adhere to Eysenck's phenotypic conceptualization of a normality-psychosis continuum without any qualitative distinction [9].

\section{$P$ as a Genetic Predisposition Factor}

In the genotypic version of the second presupposition, $\mathrm{P}$ relates to a diathesis-stress theory of psychotic disorder, in which the genetic influences believed to cause the development of both schizophrenia and manic-depression (and also of other psychoses and non-psychotic conditions, like psychopathy and criminality) are assumed to be constituted of genes of small value whose effects are additive [6]. In this version of the model, the degree of Psychoticism is held to be determined by the number of active genes involved, as well as by environmental factors. In addition, the model pos- 
tulates one or more large effect genes that, if present, will produce the sort of 'classical' psychoses recognized by Kraepelin, or - more likely in Eysenck's view - 'a large number of more sharply delineated categories normally subsumed within these great groups of psychotic disorder' [6]. However, in most cases, the genes of large effect are believed to be absent, illustrating the importance attributed to $\mathrm{P}$ as a general factor and Eysenck's claim that schizophrenia and manic-depression have much in common, both phenotypically and genotypically. With this polygenic view, the associated $\mathrm{P}$ scale is defined as 'a phenotypic measure of the hypothetical genetic predisposition towards psychotic behaviour' [68], also claiming, of course, that the same predisposition extends 'into the psychopathic and criminal, antisocial field, but not into that of the dysthymic neuroses' [46].

The interpretation of $\mathrm{P}$ as an unspecific vulnerability factor with respect to psychosis is clearly at variance with Eysenck's original and phenotypic conceptualization of that dimension. Whereas a high position on $\mathrm{P}$ in the phenotypic model is indicative of the presence of psychotic features, a high $\mathrm{P}$ score in the genotypic model is only related to a greater chance of being affected by a psychotic illness. Occasionally, this is pointed out by Eysenck himself. Thus Eysenck \& Eysenck [25] state that a high (genotypic) P score 'is a far cry from actual psychosis, and only a very small proportion of people with high P scores are likely to develop psychosis in the course of their lives'. Hence, it is rather peculiar that on other occasions these very different continua have been regarded as one and the same dimension (e.g., [9]). The distinction between both conceptualizations also becomes apparent if we compare Eysenck's original P scale [69] with the one - the P scale of the EPQ - finally arrived at. Although not fully representative of the phenotypic approach, the initial P scale contains several items that seem at face value to measure psychotic-like features [70], whereas these features are not mentioned in the contents of the EPQ P scale, a scale that completely adheres to the genotypic model. This agrees with the observation that the original $\mathrm{P}$ scale turns out to correlate very low $(r=0.19)$ with the P scale of the EPQ [71].

At least partly due to Eysenck's mixing up of his phenotypic and genotypic insights, the EPQ P scale has often been uncritically criticized for its contents. It is particularly the fact that many items in the EPQ P scale relate to such features as callousness, impulsivity, and egocentricity that has proved to most critics - sticking in effect to Eysenck's phenotypic conceptualization - that the EPQ P scale could not be regarded a valid measure of psychoticism (see, e.g., [19]). A related criticism concerns the observation that, on this scale, schizophrenic patients show only slightly raised scores [72], whereas high P scores have been found in criminals and other individuals with socially deviant behavior, including, for instance, violent people and drug addicts [9]. However, for Eysenck, the latter findings actually count in favor of the validity of the EPQ P scale, as in his view socially deviant behavior is based on the same genotype as schizophrenia and other psychoses. Although this common genotype does not exist, the above-mentioned genetic link between schizophrenia and 'affective style' and 'behavioral style' ingredients of psychopathy illustrates that Eysenck's view is not completely mistaken. Moreover, the validity of the EPQ P scale seems indicated by the fact that the scale, as regards content, agrees well with former descriptions of the schizoid personality, which may not only be present among biological relatives of schizophrenics, but may also be observed prior to schizophrenic breakdown [73]. It is this psychopathic content that makes the EPQ P scale a measure of those personality characteristics that are elsewhere described as defining the schizotypy factor Impulsive Nonconformity [74] or Asocial Schizotypy [53,75], and not a measure of those features associated with the remaining schizotypy factors Positive Schizotypy, Negative Schizotypy, and Cognitive Disorganization. Given this limitation, it seems not only appropriate to replace the usual idea of one single, unobservable, and continuously distributed variable termed liability or predisposition to schizophrenia [76] by a model in which three [75] or four [74] vulnerability factors operate, but also to redefine Eysenck's EPQ P dimension as a factor that only accounts for the emergence of antisocial conduct, both in prodromal and full-blown schizophrenia, and also in schizoid disease [75].

Admitting, then, that at least some psychopathic features are rightly assessed by the EPQ P scale, it must also be noted that these features are not the only characteristics that typify the contents of that scale. Several items, when scored in the direction opposite to the scale key, appear to indicate the presence of traits like carefulness, cleanliness, and punctuality that are often denoted in the clinical literature as features that may precede the onset of unipolar or major depression, and possibly also of bipolar disorder [47]. Hence, it appears that Eysenck's EPQ P dimension is actually built up of two subfactors that refer, respectively, to the 'antisocial' component of the pre-schizophrenic personality and to a cluster of personality traits that may precede the onset of unipolar depression. The two-components view on $\mathrm{P}$ agrees with a factor analytic study conducted by Roger \& Morris [77] in which it was demonstrated that the EPQ P dimension breaks down into two subfactors: a factor primarily concerned with 'callousness, suspiciousness, intolerance and self-serving attitudes' and a factor that, if reversed, is associated with 'punctuality, orderliness, and caution'.

\section{Proportionality Analysis}

To prove that the label Psychoticism literally applies to the EPQ P scale, we have to demonstrate, according to Eysenck, that the same biological and other variables that discriminate between psychotics and normals are also capable to discriminate between high $\mathrm{P}$ and low $\mathrm{P}$ scorers. It is this demonstration - executed by means of proportionality analysis - that in Eysenck's view is most closely connected with the application of the theory-informed approach in personality psychology. Noting that several variables - and particularly those selected for their relationship with putatively fundamental processes occurring in psychotic patients (among them low platelet MAO activity and SPEM dysfunction) showed the expected effects, Eysenck concluded that it would seem difficult to account for these findings on grounds other than the admission of a continuum ranging from the normal to the psychotic, with gradings both within the normal and the psychotic portion' [9]. However, as Eysenck's conclusion already hints at, the phenotypic and the genotypic P models are again mixed up, because the pheno- 
typic continuum hypothesis is said to be supported by proportional effects that include high and low scores on a vulnerability scale that only measures the probability of being affected by psychotic illness. A further complication stems from the fact that the variables subjected to proportionality analysis have nearly always been found to only discriminate schizophrenic patients from normals, and, so - even apart from Eysenck's unjustified claim that the methodology of proportional effect has actually demonstrated the existence of a phenotypic continuum - it seems better to speak of a continuum spanning the bridge between normality and schizophrenia. Still better, an interpretation of the proportionality findings may be preferred which takes account of the fact that several variables that originally were found to discriminate between schizophrenics and normals were also found to make a distinction between biological relatives of schizophrenics and normals (see, e.g., [78]). From this perspective, these variables may actually be seen as markers of the genetic vulnerability to schizophrenia. The demonstrated proportionality effects may thus offer a strong indication that Eysenck's EPQ P scale might be considered a phenotypic measure of the hypothetical genetic predisposition towards (only) schizophrenia and schizophrenic spectrum disorders. As the EPQ P scale is at least in part a measure of Asocial Schizotypy (see above), the meaning of this scale must be further curtailed by stating that the genetic predisposition represented by this scale only accounts for the emergence of the above-mentioned schizoid manifestations of psychopathic behavior in patients suffering from schizophrenia and schizophrenic spectrum disorders. It is from this perspective, that we may also criticize Eysenck's [9] contention that the demonstrated relationship between low Extraversion and high Neuroticism, on the one hand, and the schizotypy factors Negative Schizotypy and Cognitive Disorganization, on the other [74], simply indicates that most schizotypy scales, 'in view of the genetic distinctiveness of neurotic and psychotic disorders', are obviously unsound and that only EPQ $\mathrm{P}$ measures Psychoticism. Given the above, a completely different picture emerges, according to which the premorbid personality of later schizophrenic patients is not only characterized by schizoid psychopathic features (P), but also by low $\mathrm{E}$ and high $\mathrm{N}$ characteristics. These latter characteristics are also recognized in the clinical literature in the form of, for instance, social withdrawal, tension, and oversensitive behavior (see, e.g., $[56,73,79])^{5}$.

\section{AN ALTERNATIVE CONCEPTUALIZATION: THE 5DPT MODEL}

\section{The Dimensions $\mathbf{S}$ and $\mathbf{G}$}

From the above, it appears that the genotypic variant of Eysenck's Psychoticism model has two fundamental shortcomings, which, however, are easy to repair. First, it was noted that a factor similar to EPQ P - or rather to Roger \& Morris' subfactor 'Callousness' [77] - must be postulated that, unlike Eysenck's conceptualization of $\mathrm{P}$, stands for the phenotypic expression of a genetically-based predisposition towards antisocial or 'psychopathic' conduct in schizophre-

\footnotetext{
${ }^{5}$ The importance of $\mathrm{E}$ and $\mathrm{N}$ in the field of psychosis is also indicated by the fact that high $\mathrm{E}$ appears to be associated with the onset of mania [80] and high $\mathrm{N}$ with unipolar depression [81]. In addition, $\mathrm{N}$ describes the susceptibility to neurotic illnesses [82].
}

nia and related spectrum disorders. Second, the EPQ P construct - or in fact low $\mathrm{P}$ - was found to enclose a subfactor 'Punctuality', which appeared to describe one component of the pre-morbid personality structure that determines the probability of being affected by unipolar depression and, perhaps, by bipolar disorder. Based on these views, but also recognizing the lack of factor invariance and other psychometric deficiencies associated with the EPQ P scale [44,83], we constructed two inventories - the 3DPT or ThreeDimensional Personality Test [44] and the 4DPT or FourDimensional Personality Test [47]. In these instruments, scales for $\mathrm{E}$ and $\mathrm{N}$ were retained, but the $\mathrm{P}$ scale was replaced by one, respectively two scales that were called $S$ or Insensitivity and $\mathrm{G}$ or Orderliness. These scales were found to be reliable, to refer to highly invariant factors, and to show expected relationships with several validity criteria $[47,75]$.

\section{The Search for a 'Fifth' Dimension}

With the establishment of the 4DPT model, we may say to have arrived at an updated version of Eysenck's PEN model, consisting of the orthogonal dimensions E, N, S and $\mathrm{G}$, of which $\mathrm{S}$ and $\mathrm{G}$ were derived on the basis of our criticisms on Eysenck's genotypic P model. Nevertheless, there is still one dimension postulated by Eysenck - the phenotypic $\mathrm{P}$ dimension - that has no place in the 4DPT model. Naturally, being a phenotypic construct, this situation makes sense, but because Eysenck's normality-psychosis continuum partly refers to normal personality characteristics that are apparently assumed to underlie, and have an intrinsic relationship with, psychotic symptoms, these normal personality characteristics have also a genotypic or predispository status. Unfortunately, Eysenck nowhere presents a description of these normal personality traits. The only thing we know is that the phenotypic $\mathrm{P}$ dimension appears to have a near-zero correlation with EPQ P (see above).

To indicate someone's position on the normalitypsychosis continuum, use can be made of such measures as Eysenck's original P scale or the O-LIFE Unusual Experiences scale developed by Mason, Claridge \& Jackson [84]. However, given the fact that for the 4DPT scales S, E, N, and $G$ no items were formulated that are clearly outside the normal range, we are simply not interested in the use of that kind of scales if we want to extend the 4DPT. Moreover, if Eysenck's normality-psychosis continuum exists, then there is every reason to only emphasize those characteristics that may underlie psychosis but are in fact relatively benign. So, the question arises which personality features, if any, may be selected to define a scalable trait that shares certain properties with psychosis, but that nevertheless refers only to higher or lower degrees of normal personality functioning.

There are a few indications that the trait we are looking for must have something to do with the FFM dimension Openness to Experience $(\mathrm{O})$. In a factor analytic study by Rawlings \& Freeman [85], several inventories, among which Mason et al.'s O-LIFE and the NEO-PI-R, yielded five factors that were interpretable as Neuroticism, Extraversion, Agreeableness, Conscientiousness, and Openness to Experience. The here most interesting fact is that the Openness factor was partly defined by an - albeit modest - loading from the O-LIFE Unusual Experiences scale, a scale for the 
measurement of positive schizotypy. Similar results were obtained in a study by Wiggins \& Pincus [86]. It may be then that the cognitive and perceptual aberrations that are seen in schizotypal personality disorder and in psychosis might somehow relate to a high position on $\mathrm{O}$. If we further postulate that psychosis and psychotic-like states are characterized by a high degree of openness to all sorts of incoming stimuli, then Openness to Experience might be considered to denote a fundamental property, indeed bridging the cleft between psychosis and normality.

\section{From Openness to Absorption}

Unfortunately, several findings shed doubt on this conclusion. For instance, in Austin \& Deary's survey of correlational studies, consistent FFM correlations are only apparent between schizotypal personality disorder and Neuroticism, (low) Extraversion, and (low) Agreeableness [87]. Hence, given our expectation that $\mathrm{O}$ seems likely to be useful in assessing the aberrant perceptions and beliefs of the schizotype, the studies that suggest otherwise require an explanation.

One particular helpful explanation seems provided by Widiger, Trull, Clarkin, Sanderson \& Costa [88]. Instead of looking at the total Openness to Experience construct, the prediction was formulated that only high positions on the NEO-PI facets O1 (Openness to Fantasy), O5 (Openness to Ideas), and O6 (Openness to Values) and low positions on $\mathrm{O} 3$ (Openness to Feelings) would be associated with elevated scores on measures of schizotypal personality disorder. However, the only hypothesis that could be confirmed in several studies was the prediction of a positive relationship with $\mathrm{O} 1$. Although not anticipated, positive correlations with O2 (Openness to Aesthetics) and O3 did also emerge. Of, perhaps, greatest interest is an investigation by Ross, Lutz \& Bailly executed in a sample of female and male students [89]. Instead of using overall scales for schizotypy or schizotypal personality disorder, separate scales were administered for the assessment of positive and negative symptoms. Of the six Openness facets, O1, O2, and O5 turned out to correlate significantly in the subgroup males with the two scales administered for positive schizotypy. Moreover, in the subgroup males, a significant correlation was found between $\mathrm{O} 3$ and one of these scales. However, in the subgroup females, only $\mathrm{O} 2$ appeared to correlate with the two scales, whereas O5 was found to correlate significantly with one scale.

From the above, it seems apparent that particularly the Openness facets $\mathrm{O} 1, \mathrm{O} 2$, and $\mathrm{O} 3$ may have something to do with - or even represent - the normal personality dimension we are looking for to connect normality with psychosis. Actually, however, we may go one step further by realizing that exactly the same three facets have been found in several studies to be associated with a more broadly defined dimension of normal personality functioning, namely, Openness to Absorbing and Self-Altering Experiences, or in short Absorption [90]. According to a study by McCrae \& Costa [91], for instance, only the NEO-PI facet scales O1, O2, and $\mathrm{O} 3$ turned out to correlate rather substantially with the Absorption scale contained in Tellegen's Multidimensional Personality Questionnaire (MPQ) [92], and not the facet scales O4, O5, and O6. Similar findings were obtained by Church [93]. A study by Glisky, Tataryn, Tobias, Kihlstrom \& McConkey demonstrated that a joint factor analysis of the six NEO-PI Openness facet scales and nine subscales of the MPQ Absorption scale resulted in two factors, of which the first one was characterized by relatively high loadings from all Absorption subscales plus $\mathrm{O} 1, \mathrm{O} 2$, and $\mathrm{O} 3$, and the second one by relatively high loadings from O4, O5, and O6 [94]. Against this background, it seems understandable that Absorption has been found to be related to daydreaming, fantasy proneness, and ratings of the importance of music and art to daily life [95].

\section{Absorption and Eysenck's Theory-Informed Approach}

When considering extending the 4DPT model by a 'fifth' dimension, Eysenck's theory-informed methodology requires that such a dimension must rest on a general and causal theory that has been tested experimentally, or that at least permits experimental testing. Presently, however, a strong nomological network for Absorption has not been formulated. On the other hand, several empirical findings exist that are consistent with the role of Absorption as a vulnerability factor for psychosis, or that even suggest specific biological mechanisms that underlie the generation of behaviors represented by that dimension. Thus, in hypothesizing that our 'fifth' dimension is actually Absorption, we are at least proceeding in a manner comparable to or consistent with Eysenck's approach.

In a study conducted by Thalbourne, Bartemucci, Delin, Fox \& Nofi, both a clinical and a control sample were subjected to Tellegen's Absorption scale and to several inventories measuring different features supposed to form part of Thalbourne's Transliminality construct [96]. The term Transliminality refers to a set of correlated phenomena that are characterized by a 'susceptibility to, and awareness of, large volumes of imagery, ideation and affect - these phenomena being generated by subliminal, supraliminal and/or external input' [96]. The Transliminality features investigated in the mentioned study were paranormal beliefs and experiences, magical ideation, manic-like experiences, creativity, and mystical experience. Most important here is that the Tellegen Absorption scale emerged to correlate with magical ideation, which was assessed by the similarly termed scale of Eckblad \& Chapman [97]. However, the remaining four facets of Transliminality were also found to correlate with Tellegen's Absorption scale. This was the reason for Thalbourne to add the Absorption construct to the variables already supposed to measure Transliminality. Other variables, then or later on also assumed to be core constituents of the Transliminality factor, are schizotypal personality, unusual experiences, fantasy proneness, dissociation, general religiosity, hallucinatory predisposition, frequency of dream interpretation, hyperesthesia, and a positive attitude towards dream interpretation (see, e.g., [98]).

From our perspective, not all correlations between these variables and Tellegen's Absorption construct are equally interesting. In fact, based on the correlations between 16 Transliminality scales (including Absorption), Thalbourne conducted a principal components analysis with the expectation that all variables would yield one underlying factor, interpretable as Transliminality [99]. However, the analysis resulted in three correlated factors, that in our view (based on data provided by Thalbourne; Personal communication, 
November 18,2002) must be interpreted as Reality Changes (with high loadings from unusual experiences, hallucinatory predisposition, magical ideation, schizotypy, absorption, fantasy proneness and two dissociation measures), Spiritual Experiences (religiosity, mystical experience, and paranormal belief), and Creativity (creative personality), respectively. Hence, from our perspective, it is particularly the first-mentioned factor with its high loadings from both Tellegen's Absorption scale and several measures of positive schizotypy that might further strengthen our confidence in the Absorption dimension as a variable relevant for the development of psychotic-like and psychotic symptoms.

Just like Thalbourne's (intended) Transliminality construct $^{6}$, the factor Reality Changes combines various features, ranging from absorption and fantasy proneness, which represent more or less normal personality variations, to psychotic-like features, and, extending this range, probably even to psychotic characteristics. Of course, we may regard all facets of Reality Changes to define one and the same domain, without paying attention to the situation that the various facets appear to be phenotypically different. In doing so, we may follow Watson who has noted that individual differences in schizotypal, dissociative and sleep experiences all seem to 'reflect the ease with which a person can pass between different states of consciousness' [100]. We may even present a psychophysiological explanation of this greater permeability by speculating about a hyperconnectivity between temporal-limbic structures and sensory association cortices [101] or about the possibility, mentioned by McCreery [102], that Stage 1 sleep phenomena (and not REM sleep phenomena), under the influence of hyperarousal, briefly intrude into waking consciousness. Evidence, discussed by Ott, Reuter, Hennig \& Vaitl, also suggests a common biological basis of absorption and positive symptoms of schizophrenia [103].

Instead of the common factor, the separate facets of Reality Changes may also be given attention. In this respect, it is particularly the Absorption dimension that takes a special place. Unlike, for instance, magical ideation, Absorption is defined by Tellegen [104] as a capacity to enter dissociative and other phantasy-based experiences; therefore, this personality dimension seems to initiate other manifestations of Reality Changes. This causative view on Absorption fits well with Allen \& Coyne's continuum of detachment that was introduced to describe several stages in the progression to psychosis in patients suffering from complex trauma-related disorders [105]. On this continuum, Absorption is assumed to lead to depersonalization and derealization (dissociative detachment), and may finally result in an inward flight into a world of traumatic images and affects, 'with all the earmarks of psychotic experience'. Recent research by Van Kampen, Maurer, An der Heiden \& Häfner [106], testing Van Kampen's [53] SSQ model of prodromal unfolding in a sample of first-episode schizophrenic patients, corroborates this view in that it could demonstrate that four symptoms indicative of a process of progressive estrangement on Allen $\&$ Coyne's detachment continuum had their mean times of

\footnotetext{
${ }^{6}$ Actually, a new set of 9 facets (also embracing absorption) was finally proposed by Thalbourne that led to the extraction of only one Transliminality factor [99].
}

onset associated with gradually higher positions on a standardized continuum that reflects proportion of total prodrome time.

Summarizing the above, we may conclude that whereas the various manifestations of Reality Changes define a common factor that probably rests on enhanced boundary permeability (and on the above-mentioned biological factors that seem to explain this greater permeability), only Absorption plays a causative role with respect to the emergence of other features related to this factor. Hence, Absorption seems the trait we are looking for to connect normality with psychosis and to delineate the normal pole of Eysenck's normality-psychosis continuum. However, unlike Eysenck's phenotypic claim for P (see above), a high score on Absorption does not necessarily indicate the presence of psychosis. It is only if we regard Absorption as a weak form of impaired reality testing, and derealization, depersonalization, psychotic-like and psychotic symptoms gradually more serious manifestations of it, that we may speak of a continuum that 'goes all the way from the perfectly normal, rational to the completely insane, psychotic individual' [61]. It is clear, however, that impaired reality testing - given its phenotypically different manifestations - can not be regarded a single scalable quality on which individuals differ from each other by having higher or lower degrees of it. So, after all, we must arrive at the conclusion that Eysenck's phenotypic $\mathrm{P}$ continuum can only be kept upright in terms of a nonscalable attribute (impaired reality testing) but not if we want to single out the personality features (Absorption) which lie at the normal extreme of that continuum.

\section{The Five-Dimensional Personality Test}

Given the conclusion that is seems possible to extend the 4DPT with a scale to assess Absorption (A), the 5DPT or Five-Dimensional Personality Test was constructed. Details about its development, as well as information about the psychometrics and validity of the 5DPT is and will be presented elsewhere [107-111], as this paper has only the intention to give a theory-informed account of the underlying 5DPT model as an update of Eysenck's personality scheme. Suffice here to say that the 5DPT scales were found to intercorrelate almost zero, to rest on factors that are highly invariant with respect to various sample parameters ${ }^{7}$, to show adequate testretest and Cronbach's alpha reliabilities, and to exhibit patterns of correlates that support both the concurrent and construct validity of the scales. It was shown, for instance, that the 5DPT A scale correlated well with several measures that represent both the Transliminality factor Reality Changes and Allen and Coyne's detachment continuum. Moreover, the 5DPT scales for N, S, and A correlated positively, and 5DPT E negatively with Van Kampen's Schizotypic Syndrome Questionnaire, which is in agreement with clinical descriptions of the features that typify schizoid, schizotypal and pre-schizophrenic individuals [75]. Also, as expected, high $\mathrm{N}, \mathrm{S}$, and $\mathrm{G}$ scores and low E scores turned out to characterize individuals with high positions on the DAPP-BQ and DAPP-SF personality disorder dimensions Emotional

\footnotetext{
${ }^{7}$ High congruence values were also obtained after comparing the factor structures of the American-English (Dr. Coolidge; University of Colorado, USA) and Italian (Dr. San Martini; University of Rome, Italy) translations of the 5DPT with the original Dutch instrument.
} 
Dysregulation, Dissocial, Compulsivity, and Inhibition, respectively, as well as on their lower-order factors [110,111]. Interestingly, the theory-informed 5DPT scales were also found to correlate rather substantially with the NEO-FFI [107] and HEXACO-Personality Inventory scales [109], thus additionally demonstrating the comprehensiveness of the 5DPT model from a lexical point of view.

\section{CONCLUDING REMARKS}

The question may arise whether it is possible to extend the 5DPT model with other theory-informed susceptibility dimensions. However, if dimensions from other theoretical personality systems are considered, like Cloninger's psychobiological temperament and character model (e.g., [112]), the proposed dimensions appear to have much in common with both the Eysenck dimensions and the FFM factors [113]. As the 5DPT model shows a rather close correspondence with the Five Factor Model [107], and the FFM or Big Five factors Agreeableness and Conscientiou-sness negatively relate to $P[28,30]$, it seems almost certain that a similar overlap will also appear if the Cloninger scales are correlated with the 5DPT. Comparable results can be expected for other theory-based systems that relate to the PEN and FFM models, like Zuckerman's Alternative Five [114]. Conceptually, we may also infer relationships between the dimensions cognitive/perceptual organization, impulsivity/aggression, affective instability, and anxiety/inhibition in Siever \& Davis' psychobiological model and the 5DPT. These associations are interesting as the dimensions in this model were explicitly postulated to span the DSM-III-R Axis 1 and Axis II disorders [115]. Given the fact that the 5DPT was also found to correlate with the six dimensions of the HEXACO-PI [109], we may put the question whether it is possible to extend the 5DPT with one or more lexically-based dimensions that are of clinical interest (provided, of course, that a nomological network can be established). However, with respect to the issue whether lexical personality factors may be found beyond the Big Five, the literature seems divided. On the one side, most present-day researchers adhere to a version of the prevailing Big Five model; on the other, several six-factor representations, including the HEXACO model, and even models embracing seven or more factors have been propagated [31,116]. These additional dimensions are, for instance, Risk-Taking [117], Spirituality [118], and Positive and Negative Valence [116]. Though some of these dimensions have been reported more than once [119], the results are far from consistent. Furthermore, it is sometimes stated that at least some additional factors may be better conceptualized as maladaptive variants of existing Big Five dimensions [120]. With respect to the HEXACO-PI, we must also state that the dimensions Honesty and Agreeableness were found to be subfactors of 5DPT Insensitivity, mimicking the situation regarding $\mathrm{P}$ and the Big Five dimensions Agreeableness and Conscientiousness. Of course, from the perspective of the HEXACO model, the maintenance of our theory-based S dimension would logically indicate the necessity of extending the 5DPT with a 'sixth' orthogonal factor that relates to the personality features that have a positive loading on HEXACO Agreeableness in combination with a negative loading on HEXACO Honesty and vice versa. However, consulting the six-factor structure of personalitydescriptive adjectives that emerged in Ashton et al.'s study
[31] - the data were kindly provided by De Vries; Personal communication, January 6, 2009 - no adjectives were found that showed this pattern of loadings. With these objections, we regard it as unfeasible to choose for any additional dimension, even if a certain factor, like for instance RiskTaking, appears to show clinical relevance. At least for the time being, our conclusion must be that the theory-informed 5DPT model which comprises the vulnerability factors $\mathrm{S}, \mathrm{E}$, $\mathrm{N}, \mathrm{G}$, and A suffices as a psychopathology-related personality model. With each 5DPT dimension (eventually) embedded in a strong nomological network that relates to findings in genetics, physiology, neuropsychology, learning theory, etc., the 5DPT model might be expected to offer an adequate and integrated explanatory framework for studying the frequency and patterns of overlap between personality and psychopathology.

\section{REFERENCES}

[1] Gunderson JG, Triebwasser J, Phillips KA, Sullivan CN. Personality and vulnerability to affective disorders. In: Cloninger CR, Ed. Personality and psychopathology. Washington DC: American Psychiatric Press 1999; pp. 3-32.

[2] Kraepelin, E. Psychiatrie: Ein Lehrbuch für Studierende und Ärzte. 8th edition. Leipzig: Barth 1913.

[3] Sullivan HS. The theory of anxiety and the nature of psychotherapy. Psychiatry $1949 ; 12: 3-12$.

[4] Maher BA, Maher WB. Personality and psychopathology: A historical perspective. J Abnorm Psychol 1994; 103: 72-7.

[5] Eysenck HJ. Dimensions of personality. London: Routledge and Kegan Paul 1947.

[6] Eysenck HJ, Eysenck SBG. Psychoticism as a dimension of personality. London: Hodder and Stoughton 1976.

[7] Eysenck HJ. The dynamics of anxiety and hysteria. London: Routledge and Kegan Paul 1957.

[8] Eysenck HJ. The biological basis of personality. Springfield: Thomas 1967.

[9] Eysenck HJ. The definition and measurement of Psychoticism. Pers Indiv Diff 1992b; 13: 757-85.

[10] Eysenck HJ. The importance of theory in the taxonomy of personality. In: De Raad B, Hofstee WKB, Van Heck GL, Eds. Personality psychology in Europe. Tilburg: Tilburg University Press, The Netherlands 1994a; vol. 5: pp. 6-13.

[11] Eysenck HJ. (1994b). The Big Five or Giant Three: Criteria for a paradigm. In: Halverson CF, Kohnstamm GA, Martin RP, Eds. The developing structure of temperament and personality from infancy to adulthood. Hillsdale, NJ: Lawrence Erlbaum Associates 1994b; pp. 37-51.

[12] Cronbach LJ, Meehl PE. Construct validity in psychological tests. Psychol Bull 1955; 52: 281-302.

[13] Pervin LA. Personality: theory, assessment and research. New York: Wiley 1980.

[14] Goldberg LR. An alternative 'description of personality': The BigFive factor structure. J Pers Soc Psychol 1990; 59: 1216-29.

[15] Costa PT, McCrae RR. The NEO Personality Inventory Manual. Odessa: Psychol Assessment Resources 1985.

[16] Ashton MC, Lee K. The lexical approach to the study of personality structure: toward the identification of cross-culturally replicable dimensions of personality variations. J Pers Disord 2005; 19: 3038.

[17] Davis H. What does the P scale measure? Br J Psychiatr 1974; 125: 161-7.

[18] Bishop DVM. The P scale and psychosis. J Abnorm Psychol 1977; 86: $127-34$.

[19] Zuckerman M, Kuhlman DM, Camac C. What lies beyond E and $\mathrm{N}$ ? Factor analyses of scales believed to measure basic dimensions of personality. J Pers Soc Psychol 1988; 54: 96-107.

[20] Widiger TA, Verheul R, Van den Brink W. Personality and psychopathology. In: Pervin LA, John OP, Eds. Handbook of personality: Theory and research. New York: Guilford Press 1999; pp. 34766. 
[21] Saucier G, Goldberg LR. The language of personality: lexical perspectives on the five-factor model. In: Wiggins JS, Ed. The fivefactor model of personality: Theoretical perspectives. New York: Guildford Press 1996; pp. 21-50.

[22] Costa PT, McCrae RR. Four ways five factors are basic. Pers Indiv Diff 1992; 13: 653-65.

[23] Silk KR. Axis I - Axis II interactions. J Psychiat Res 1996; 30: 3-7.

[24] Widiger TA, Samuel DB. Diagnostic categories or dimensions? A question for the the Diagnostic and Statistical Manual of Mental Disorders $-5^{\text {th }}$ ed. J Abnorm Psychol 2005; 114: 494-504.

[25] Eysenck SBG, Eysenck HJ. Manual of the Eysenck Personality Questionnaire. London: Hodder and Stoughton 1975.

[26] Eysenck HJ. Dimensions of personality: 16, 5 or 3? - Criteria for a taxonomic paradigm. Pers Individ Dif 1991; 12: 773-90.

[27] Eysenck HJ. Four ways five factors are not basic. Pers Indiv Diff 1992a; 13: 667-73.

[28] Goldberg LR, Rosolack TR. The Big Five factor structure as an integrative framework: An empirical comparison with Eysenck's PE-N model. In: Halverson CF, Kohnstamm GA, Martin, RP, Eds. The developing structure of temperament and personality from infancy to adulthood. Hillsdale, NJ: Lawrence Erlbaum Associates 1994; pp. 7-35.

[29] Markon KE, Krueger RF, Watson D. Delineating the structure of normal and abnormal personality: an integrative hierarchical approach. J Pers Soc Psychol 2005; 88: 139-57.

[30] McCrae RR, Costa PT. Comparison of EPI and psychoticism scales with measures of the five-factor model of personality. Pers Individ Dif 1985a; 6: 587-97.

[31] Ashton MC, Lee K, Perugini M, Szarota P, De Vries RE, Di-Blas L, Boies K, De-Raad B. A six-factor structure of personalitydescriptive adjectives: Solutions from psycholexical studies in seven languages. J Pers Soc Psychol 2004; 86: 356-66.

[32] Plomin R, Asbury K, Dunn J. Why are children in the same family so different? Nonshared environment a decade later. Can J Psychiatr 2001; 46: 225-33.

[33] Rutter M. Temperament, personality, and personality development. Br J Psychiatry 1987; 150: 443-8.

[34] Rutter M, Maughan B. Psychosocial adversities in psychopathology. J Pers Disord 1997; 11: 19-33.

[35] Paris J. Nature and nurture in personality disorders. In: Strack S, Ed. Handbook of personality and psychopathology. New York: Wiley 2005; pp. 24-38.

[36] Cattell RB. The description of personality: Basic traits resolved into clusters. J Abnrom Soc Psychol 1943; 38: 476-506.

[37] Goldberg LR. From Ace to Zombie: Some explorations in the language of personality. In: Spielberger CE, Butcher JN, Eds. Advances in personality assessment, Vol. 1. Hillsdale, NJ: Erlbaum 1982; vol. 1; pp. 203-234.

[38] Allport GW. Pattern and growth in personality. New York: Rinehart and Winston 1961.

[39] Block J. A contrarian view of the five-factor approach to personality description. Psychol Bull 1995; 117: 187-215.

[40] Eysenck HJ. How valid is the psychoticism scale? A comment on the Van Kampen critique. Eur J Pers 1995; 9: 103-8.

[41] Eysenck HJ. Personality and experimental psychology: The unification of psychology and the possibility of a paradigm. J Pers Soc Psychol 1997; 73: 1224-37.

[42] Goldberg LR. The structure of phenotypic personality traits. Am Psychologist 1993; 48: 26-34.

[43] Eysenck HJ. A reply to Costa and McCrae: P or A and C - The role of theory. Pers Individ Diff 1992c; 13: 867-8.

[44] Van Kampen D. The 3DPT dimensions S, E, and N: A critical evaluation of Eysenck's Psychoticism model. Eur J Pers 1993; 7: 65-105.

[45] Andreasen NC. The diagnosis of schizophrenia. Schizophr Bull 1987; 13: 9-22.

[46] Eysenck HJ. An experimental and genetic model of schizophrenia. In: Kaplan AR, Ed. Genetic factors in 'schizophrenia'. Springfield, IL: Thomas 1972; pp. 504-15.

[47] Van Kampen D. Orderliness as a major dimension of personality: From 3DPT to 4DPT. Euro J Pers 1997; 11: 211-42.

[48] Kendler KS, Gardner CO. The risk for psychiatric disorders in relatives of schizophrenic and control probands: a comparison of three independent studies. Psychol Med 1997; 27: 411-9.

[49] Maier W, Hallmayer J, Minges J, Lichtermann D. Affective and schizoaffective disorders: Similarities and differences. In:
Marneros A, Tsuang MT, Eds. Morbid risks in relatives of affective, schizoaffective, and schizophrenic patients: results of a family study. New York: Springer Verlag 1990; pp. 201-7.

[50] Berrettini WH. Susceptibility loci for bipolar disorder: Overlap with inherited vulnerability to schizophrenia. Biol Psychiatry 2000 47: 245-51.

[51] Cardno AG, Rijsdijk FV, Sham PC, Murray RM, McGuffin P. A twin study of genetic relationships between psychotic symptoms. Am J Psychiat 2002; 159: 539-45.

[52] Docherty JP, Van Kammen JP, Siris SG, Marder SR. Stages of onset of schizophrenic psychosis. Am J Psychiat 1978; 135: 420-6.

[53] Van Kampen D. Pathways to schizophrenic psychosis: A LISRELtested model of the unfolding of the schizophrenic prodrome. J Clin Psychol 2005; 61: 909-38.

[54] Baron M, Gruen R, Rainier JD, Kane J, Asnis L, Lord S . A family study of schizophrenic and normal control probands: Implications for the spectrum concept of schizophrenia. Am J Psychiat 1985; 142: 447-55.

[55] Andreasen NC, Flaum M. Schizophrenia: the characteristic symptoms. Schizophr Bull 1991; 17: 27-49.

[56] Kallmann FJ. The genetics of schizophrenia. New York: Augustin 1938 .

[57] Cooke DJ, Michie C. Refining the construct of psychopathy: Towards a hierarchical model. Psychol Assess 2001; 13: 171-88.

[58] Slater E. Psychotic and neurotic illnesses in twins. Medical Research Council Special Report Series, no. 278. London: Her Majesty's Stationery Office 1953.

[59] Heston LL. Psychiatric disorders in foster home reared children of schizophrenic mothers. Br J Psychiatry 1966; 112: 819-25.

[60] Torgersen S, Onstad S, Skre I, Edvardsen J, Kringlen E. 'True' schizotypal personality disorder: a study of co-twins and relatives of schizophrenic probands. Am J Psychiat 1993; 150: 1661-7.

[61] Eysenck HJ. Schizothymia-Cyclothymia as a dimension of personality: II. Experimental. J Pers 1952; 20: 345-84.

[62] Kendell RE. The role of diagnosis in psychiatry. Oxford: Blackwells 1975.

[63] Johns L, Van Os J. The continuity of psychotic experiences in the general population. Clin Psychol Rev 2001; 21: 1125-41.

[64] Vollema MG, Van den Bosch RJ. The multidimensionality of schizotypy. Schizophrenia Bull 1995; 21: 19-31.

[65] Bentall RP, Claridge GS, Slade PD. The multidimensional nature of schizotypal traits: A factor analytic study with normal subjects. Brit J Clin Psychol 1989; 28: 363-75.

[66] Liddle PF. The symptoms of chronic schizophrenia: A reexamination of the positive-negative dichotomy. $\mathrm{Br} \mathrm{J}$ Psychiat 1987; 151: 145-51.

[67] Claridge G. Single indicator of risk for schizophrenia: Probable fact or likely myth? Schizophrenia Bull 1994; 20: 151-68.

[68] Eaves LJ, Eysenck HJ. A genotype-environmental model for Psychoticism. Adv Behav Res Ther 1977; 1: 5-26.

[69] Eysenck SBG, Eysenck HJ. The measurement of Psychoticism: A study of factor stability and reliability. Br J Soc Clin Psychol 1968; 7: 286-94.

[70] Claridge G. Psychoticism. In: Lynn R, Ed. Dimensions of personality: papers in honour of H.J. Eysenck. Oxford: Pergamon Press 1981; pp. 79-109.

[71] Claridge G, Robinson DL, Birchall P. Characteristics of schizophrenics' and neurotics' relatives. Pers Individ Diff 1983; 4: 65164.

[72] Block J. Eysenck Personality Questionnaire. In: Buros OK, Ed. The eighth mental measurements yearbook. Highland Park: Gryphon Press 1978; Vol. 1: pp. 805-9.

[73] Bleuler M. Die schizophrenen Geistesstörungen im Lichte langjähriger Kranken- und Familiengeschichten. Stuttgart: Thieme 1972.

[74] Claridge G, McCreery C, Mason O, Bentall R, Boyle G, Slade P, Popplewell D. The factor structure of 'schizotypal' traits: a large replication study. Br J Clin Psychol 1996; 35: 103-15.

[75] Van Kampen D. The Schizotypic Syndrome Questionnaire (SSQ): Psychometrics, validation and norms. Schizophr Res 2006; 84: 305-22.

[76] Faraone SV, Tsuang MT. Quantitative models of the genetic transmission of schizophrenia. Psychol Bull 1985, 98: 41-66.

[77] Roger D, Morris J. The internal structure of the EPQ scales. Pers Individ Dif 1991; 12: 759-64. 
[78] Buchsbaum MS, Coursey RD, Murphy DL. The biochemical highrisk paradigm: Behavioral and familial correlates of low platelet monoamine oxidase activity. Science 1976; 194: 339-41.

[79] Kretschmer E. Körperbau und Character: Untersuchungen zum Konstitutionsproblem und zur Lehre von den Temperamenten. Berlin: Springer 1929.

[80] Eckblad M, Chapman LJ. Magical ideation as an indicator of schizotypy. J Consult Clin Psychol 1983; 51:215-25.

[81] Clayton PJ, Ernst C, Angst J. Premorbid personality traits of men who develop unipolar or bipolar disorders. Eur Arch Psychiatr Clin Neurosci 1994; 243: 340-6.

[82] Claridge G, Davis C. What's the use of neuroticism? Pers Indiv Diff 2001; 31: 383-400.

[83] Van Kampen D. De Personality Questionnaire van Eysenck en Eysenck: Een factoranalytisch onderzoek. Nederl Tijdschr Psychol 1976; 31: 23-34.

[84] Mason O, Claridge G, Jackson M. New scales for the assessment of schizotypy. Pers Indiv Diff 1995; 1: 7-13.

[85] Rawlings D, Freeman JL. Measuring paranoia/suspiciousness. In: Claridge G, Ed. Schizotypy: implications for illness and health. Oxford: Oxford University Press 1997; pp. 38-60.

[86] Wiggins JS, Pincus AL. Conceptions of personality disorders and dimensions of personality. Psychol Assessment 1989; 1: 305-16.

[87] Austin EJ, Deary, IJ. The 'four As': a common framework for normal and abnormal personality? Pers Individ Dif 2000; 28: 977 95.

[88] Widiger TA, Trull TJ, Clarkin J.F, Sanderson C, Costa PT. A description of the DSM-III-R and DSM-IV personality disorders with the five-factor model of personality. In: Costa PT, Widiger TA, Ed. Personality disorders and the five-factor model of personality. Washington: Am Psychol Assoc 1994; pp. 41-56

[89] Ross SR, Lutz CJ, Bailley SE. Positive and negative symptoms of schizotypy and the five-factor model: a domain and facet level analysis. J Pers Assessment 2002; 79: 53-72.

[90] Tellegen A, Atkinson G. Openness to absorbing and self-altering experiences ('Absorption'), a trait related to hypnotic susceptibility. J Abnorm Psychol 1974; 83: 268-77.

[91] McCrae RR, Costa PT. Openness to Experience. In: Hogan R, Jones WH, Eds. Perspectives in personality. Volume 1. Greenwich: JAI Press 1985b; pp. 145-72.

[92] Tellegen A. Brief manual for the Mutidimensional Personality Questionnaire. University of Minnesota 1982.

[93] Church AT. Relating the Tellegen and five-factor models of personality structure. J Pers Soc Psychol 1994; 67: 898-909.

[94] Glisky ML, Tataryn DJ, Tobias BA, Kihlstrom JF, McConkey KM. Absorption, openness to experience, and hypnotizability. J Pers Soc Psychol 1991; 60: 263-72.

[95] Roche SM, McConkey KM. Absorption: nature, assessment, and correlates. J Pers Soc Psychol 1990; 59: 91-101.

[96] Thalbourne MA, Bartemucci L, Delin PS, Fox B, Nofi O. Transliminality: its nature and correlates. J Am Soc Psychol Res 1997; 91: 305-31.

[97] Eckblad M, Chapman LJ. Development and validation of a scale for hypomanic personality. J Abnorm Psychol 1986; 95: 214-22.

[98] Thalbourne MA, Delin PS. Transliminality: its relation to dreamlife, religiosity and mystical experience. Int J Psychol Religion 1999; 9: 45-61.

[99] Thalbourne MA. Transliminality: Further correlates and a short measure. J Am Soc Psychol Res 1998; 92: 402-19.

[100] Watson D. Dissociation of the night: individual differences in sleep-related experiences and their relation to dissociation and schizotypy. J Abnorm Psychol 2001; 110: 526-535.
[101] Thalbourne MA, Crawley SE, Houran J. Temporal lobe lability in the highly transliminal mind. Pers Individ Dif 2003; 35: 1965-74.

[102] McCreery C. Hallucinations and arousability: pointers to a theory of psychosis. In: Claridge G, Ed. Schizotypy: implications for illness and health. Oxford: Oxford University Press 1997; pp. 251-73.

[103] Ott U, Reuter M, Hennig J, Vaitl D. Evidence for a common biological basis of the absorption trait, hallucinogen effects, and positive symptoms: Epistasis between 5-HT2a and COMT polymorphisms. Am J Med Genet Part B 2005; 137B: 29-32.

[104] Tellegen A. Note on structure and meaning of the MPQ absorption scale. University of Minnesota 1992.

[105] Allen JG, Coyne L. Dissociation and vulnerability to psychotic experience: The dissociative experiences scale and the MMPI-2. J Nerv Ment Dis 1995; 183: 615-22.

[106] Van Kampen D, Maurer K, An der Heiden W, Häfner H. Prodromal unfolding: The validation of the Schizotypic Syndrome Questionnaire model in a sample of first-episode schizophrenic patients. Early Interv Psychiatry 2009; 3: 137-50.

[107] Van Kampen D. The 5DPT: Construction, psychometrics and validation. Paper in preparation 2009.

[108] Coolidge FL, Segal DL, Cahill BS, Archuleta JL. A new five factor model of psychopathology: preliminary psychometric characteristics of the five-dimensional personality test (5DPT). Pers Indiv Diff 2008; 44: 1326-34.

[109] De Vries RE, Van Kampen D. The HEXACO and 5DPT models of personality: a comparison and their relationships with psychopathy, egoism, pretentiousness, immorality, and Machiavellianism. J Pers Disord 2009 (in press).

[110] Van Kampen D. The Dutch DAPP-BQ: Improvements, lower- and higher-order dimensions, and relationship with the 5DPT. J Pers Disord 2006; 20: 81-101.

[111] Van Kampen D, De Beurs E, Andrea H. A short form of the dimensional assessment of personality pathology (DAPP-BQ): The DAPP-SF. Psychiatr Res 2008; 160: 115-28.

[112] Cloninger CR, Svrakic DM, Bayon C, Przybeck TR. Measurement of psychopathology as variants of personality. In: Cloninger CR, Ed. Personality and psychopathology. Washington DC: American Psychiatric Press 1999; pp. 33-65.

[113] De Fruyt F, Van de Wiele L, Van Heeringen C. Cloninger's psychobiological model of temperament and character and the fivefactor model of personality. Pers Indiv Diff 2000; 29: 441-52.

[114] Zuckerman M, Kuhlman DM, Joireman J, Teta P, Kraft M. A comparison of three structural models for personality: The Big Three, the Big Five, and the Alternative Five. J Pers Soc Psychol 1993; 65: 757-68.

[115] Siever LJ, Davis KL. A psychobiological perspective on the personality disorders. Am J Psychiatr 1991; 148: 1647-58.

[116] Tellegen A, Waller NG. Exploring personality through test construction: Development of the Multidimensional Personality Questionnaire. In: Briggs S, Cheek J, Eds. Personality measures: Development and evaluation, Volume 1. Greenwich: JAI Press 1996.

[117] Andresen B. Six basic dimensions of personality and a seventh factor of generalized dysfunctional personality (GDP): A diathesis system covering all personality disorders. Neuropsychobiol 2000; 41: 5-23.

[118] Piedmont RL. Does Spirituality represent the sixth factor of personality? Spiritual transcendence and the five-factor model. J Pers 1999; 67: 985-1013.

[119] Saucier G, Goldberg LR. What is beyond the Big Five? J Pers 1998; 66: 495-524.

[120] Widiger TA, Trull TJ. Personality and psychopathology: an application of the five-factor model. J Pers 1992; 60: 363-93.

(C) Dirk van Kampen; Licensee Bentham Open.

This is an open access article licensed under the terms of the Creative Commons Attribution Non-Commercial License (http://creativecommons.org/licenses/by-nc/3.0/) which permits unrestricted, non-commercial use, distribution and reproduction in any medium, provided the work is properly cited. 